\title{
Recombinant Gamma Chemokine
}

National Cancer Institute

\section{Source}

National Cancer Institute. Recombinant Gamma Chemokine. NCI Thesaurus. Code C1712.

A family of synthetic or recombinant C-type chemokines lacking adjacent cysteine residues and act as chemoattractants for lymphocytes. 